\title{
An Ethnobotanical Study of Enset (Ensete ventricosum (Welw) Cheesman) in Angacha Woreda, Kembata-Tembaro Zone, South Region, Ethiopia
}

\author{
Ashenafi Ayenew, Abiyselassie Mulatu ", Bruk Lemma, Demissie Girma \\ Genetic Resources Access and Benefit Sharing Directorate, Ethiopian Biodiversity Institute, Addis Ababa, Ethiopia
}

Email address:

abiyselassiemulatu@gmail.com (A. Mulatu), ayenewashenafi2007@gmail.com (A. Ayenew)

${ }^{*}$ Corresponding author

\section{To cite this article:}

Ashenafi Ayenew, Abiyselassie Mulatu, Bruk Lemma, Demissie Girma. An Ethnobotanical Study of Enset (Ensete ventricosum (Welw) Cheesman) in Angacha Woreda, Kembata-Tembaro Zone, South Region, Ethiopia. American Journal of Life Sciences. Vol. 4, No. 6, 2016, pp. 195-204. doi: 10.11648/j.ajls.20160406.18

Received: November 8, 2016; Accepted: December 10, 2016; Published: January 12, 2017

\begin{abstract}
An ethnobotanical study was conducted on enset (Ensete ventrcosum (Welw.) Cheesman) in Angacha Woreda, Kembata Tembaro Zone, South Region, Ethiopia. The study was aimed at documenting indigenous knowledge and practices on use and conservation of enset local varieties in South Region, Ethiopia. The data were collected using semi-structured interviews, discussion, direct field observation, preference ranking, direct matrix ranking and paired comparison techniques. A total of 154 locally known enset local varieties were documented. Nine enset local varieties ('Sisqela', 'Geshera', 'Direbo', 'Leqaqa', 'Sebera', 'Ongame', 'Gembewa', 'Abatmerza' and 'Sheleqe') were found to be the most popular local varieties, cited by more than $80 \%$ of the key informants. Direct matrix ranking showed that 'Ongame', 'Direbo' and 'Sisqela' as the top most culturally important enset local varieties. Diversification was found to be the traditional management and conservation strategy of the local people. Sixty two percent of the key informants cultivated and maintained about 15-56 enset local varieties to meet with their diversified demands (nutritional, fiber, fermentative quality, high yield and disease and drought resistance). The results in the present study indicate that the local people in the study areas have a rich knowledge on use, management and conservation of enset local varieties. Therefore, in situ conservation of enset local varieties in association with their uses should be encouraged and strengthened to ensure sustainable use of this multi-purpose plant.
\end{abstract}

Keywords: Angacha Woreda, Ensete ventricosum, Ethnobotany, Indigenous Knowledge, Local Varieties

\section{Introduction}

Ethiopia is home for astonishing systems of indigenous knowledge that helped the people survive under adverse environmental conditions, including famine and poverty [1]. Farmers in Ethiopia manage their cropping systems with considerable indigenous skill. For millennia, they have been the generators and curators of the rich assemblage of crop biodiversity under their custodianship [2].

There is much to learn from indigenous modes of production, as these systems have a strong ecological basis, maintain valuable genetic diversity and lead to regeneration and preservation of biological diversity and natural resources [3]. This long-standing tradition can be instrumental for the intensification of sustainable agriculture in many parts of
Ethiopia. Therefore, indigenous knowledge and practices need to be studied and documented.

The enset-based farming system, which is characterized by cultivation of enset as a main staple or as co-stable with other crops, is one of the four farming systems existing in Ethiopia [4]. The other three are the plough and cereal complex of Northern and Central Ethiopian Highlands, the shifting cultivation economies of sub-tropical and lowland western and southwestern Ethiopia, and the pastoral complex represented by the nomadic populations in the low-lying plains [5].

Enset-based farming systems are among the most sustainable indigenous farming systems in Ethiopia and play an important role in food security [5]. Enset is cultivated as staple food only in Ethiopia [6]. This indigenous culturally 
important crop should be studied and strengthened to promote and implement the agro-climate and culture-adapted farming system. This calls for more concerned efforts in ethnobotanical studies.

This study aims at documenting and describing the indigenous knowledge and practices associated with the use and conservation of enset local varieties in Angacha Woreda (District), Kembata Tembaro Zone, South Region of Ethiopia.

This study informs the diversity, multiple uses and cultivation, harvesting and processing methods, traditional management and conservation practices of enset local varieties in Angacha Woreda, Kembata Tembaro Zone. The information helps to identify enset clones (varieties) for development and conservation priorities and contribute to the building up of the ethnobotanical database for Ethiopia.

\section{Materials and Methods}

\subsection{Description of the Study Area}

The study was conducted in Angacha Woreda, Kembata Tembaro Zone of the Southern Nations, Nationalities and Peoples' Regional State (SNNPRS). It lies between latitudes $07^{0} 30^{\prime} \mathrm{N}$ and $07^{0} 34^{\prime} \mathrm{N}$ and longitudes $037^{\circ} 83^{\prime} \mathrm{E}$ and $037^{0} 88^{\prime} \mathrm{E}$. It covers an area of 17,718 hectares. It is divided into 19 administrative units called 'Kebeles'. Angacha town is an administrative center situated about $275 \mathrm{~km}$ from Addis Ababa and bordered in the south by Kacha Bira, in the north by the Hadiya Zone, in the east by Kedida Gamela, and in the west by Deyogena. The study area has a total population of 81,264 , of whom 40,564 are males and 40,700 are females [7]. Enset is grown in southwestern part of the country and covers considerable land area within the private holdings. During the Ethiopian Agricultural Survey of 2011/2012, a total of $312,171.98$ hectares of land were found to be under enset in the country, taking up about $2.3 \%$ of the land area covered by all crops at country level and yielding about $7,288,686.96$ quintals of produce by the peasant holders, contributing to about $2.68 \%$ of the total country level all crop production [8].

\subsection{Sampling Techniques}

The study sites were determined during the first field visit based on their agro-ecological zonation and the significance of enset to this area. The study area was roughly stratified to include adequate representations of the local people in terms of agro-ecology. Therefore, a total of 10 study sites were selected for an ethnobotanical data collection based on their range of altitude. The study sites ranges in altitude from 1965 $\mathrm{m}$ (Adancho) to $2542 \mathrm{~m}$ (Zebecho), which covers nearly the entire ecological range of enset. The study sites are situated within a radius of $20 \mathrm{~km}$ from Angacha town.

A total of 100 informants (62 males and 38 females) were selected using a systematic random sampling method that represents the overall population of the community. From each study site, 10 individual informants were selected randomly. Ten key informants (6 males and 4 females) were selected based on prior information obtained from development workers, elders, authorities and religious leaders. While recording specialized knowledge held by traditional healers or by certain social groups such as children, women or the elderly, the choice of key informants is dictated [9]. In this study, therefore, selection was made systematically so that there is a fair representation of informants in which age and gender and specialist knowledge bias were avoided.

\subsection{Ethnobotanical Data Collection}

Two round ethnobotanical data collection on enset in Angacha Woreda were conducted. The first round was conducted from November 6 to December 7, 2012, and the second round from January 24 to February 22, 2013. Different anthropological techniques were employed to collect data from the study area as described in [9-11]. Semistructured interview, open-ended interview, direct field observation and group discussion were conducted to obtain qualitative data.

\subsection{Data Analysis}

The data collected through semi-structured interview, direct field observation, guided field walk and group discussion were analyzed using analytical tools of ethnobotany such as free-listing, preference ranking, direct matrix ranking and paired comparison as described in $[9,11]$.

\subsubsection{Free-Listing}

This technique was used to list all enset local varieties mentioned by informants for certain use category. The list involved local names, uses and part used. Different use categories were identified.

\subsubsection{Preference Ranking}

In this study, a total of 7 preference ranking activities were conducted for high yield, fermentation quality, early maturity, 'qocho' quality, 'bulla' quality, 'amicho' quality, and desirability. Ten key informants were selected to conduct the preference ranking exercises. They were asked to rank 6-10 enset local varieties based on their quality or personal preference for the specific use category considered under each ranking activities. The local varieties were selected by examining how frequently informants mentioned them for those specific use categories. Each rank was given an integer value $(1,2,3$, and so on) with the most important item given the highest value, while the least important was assigned a value of 1 . These numbers were summed for all respondents to give an overall ranking for the enset local varieties. This helped to indicate the most preferred enset variety for specific use.

\subsubsection{Direct Matrix Ranking}

The key informants were asked to rank ten most popular enset local varieties based on ten use criteria. They were informed to give a score of 10 for the use which they 
considered the best, 1 for the least and 0 for the uses not known for a specific use criteria. The results of 10 key informants were added together to create a matrix that is representative of the community. This method helped to identify the most top enset local varieties with diverse uses and high relative importance to the local people.

\subsubsection{Paired Comparison}

This method was employed to determine enset local varieties of high quality fiber production. In paired comparison, 5 local varieties were arranged randomly in sets of two and then the pairs were randomized. The number of pairs was established by the formula, $n(n-1) / 2$, where $n$ is the number of enset varieties. These pairs were presented to the key informants to identify the one which provides better fiber quality. A total order was obtained by summing up the number of times each local variety was chosen. The results of 10 key informants were added together to produce a matrix of aggregated score.

\section{Results}

\subsection{Diversity of Enset Local Varieties}

In this study, a total of 154 locally known enset local varieties were recorded. Of these, 65 local varieties were cited only by one of the 100 informants and 89 local varieties were cited by many of the informants. Among the 89 enset local varieties, 22 were cited only by 2-4 informants and 67 cited at least by 5 informants of the 100 informants. Among the 67 local varieties, 55 were cited at least by 10 informants, 42 cited at least by 20 informants, 33 cited at least by 30 informants and 27 cited at least by 40 informants of the 100 informants.

Only 23 local varieties were cited by more than 50 informants, 19 local varieties cited by at least 60 informants and 11 local varieties cited by more than 70 informants of the 100 informants. Nine enset local varieties ('Sisqela', 'Geshera', 'Direbo', 'Leqaqa', 'Sebera', 'Ongame', 'Gembewa', 'Abatmerza' and 'Sheleqe') were found to be the most popular enset local varieties in the study area, which were cited by at least 80 of the 100 informants.

\subsection{Emic Categories of Enset Local Varieties}

The local people classified their enset local varieties in two categories (male and female) based on 'kocho', 'bulla' and 'amicho' quality, fermentation quality, ease of processing, early maturity, yield, and resistance to disease and drought. They distinguished each variety in terms of its "maleness" or "femaleness".

The female varieties such as 'Leqaqa', 'Sebera', 'Gembewa', 'Tebere', 'Torore', 'Etene', 'Abatmerza', 'Qoyena' and 'Astra' were characterized by having best qualities of 'kocho', 'bulla' and 'amicho', fermentation quality and ease of processing and early maturity. Varieties categorized as "maleness", such as 'Direbo', 'Sisiqela', 'Geshera', 'Sheleqe', 'Ongame' and 'Dego' were characterized by poor qualities of 'kocho', 'bulla' and 'amicho', fermentation quality, difficulty of processing and late maturity. But they were also characterized as high yielder, resistant to disease and drought and as a preferred feed for cattle.

During discussion and semi-structured interview with the informants, it was reported that processing could be made by mixing enset varieties from both categories ("femaleness" and "maleness") in order to combine different qualities, such as high yield and best and preferred qualities of 'kocho', 'bulla', and 'amicho'. This may be attributed to the diversification of enset local varieties in the study area.

\subsection{Local Farming System}

Enset cultivation forms the core component of the local farming system. Every household cultivates enset (singular: 'Wesho' and plural; 'Wesse') in their homegarden as main staple food crop. The enset-based farming system in the study area also includes cereal crops (wheat, maize, sorghum, teff and barley), pulses (bean and pea), cabbage, potato, coffee, eucalyptus trees, fruit trees (mango, apple and avocado), Podocarpus falcatus, Cordia africana and other tree species.

The local people in the study area cultivate and maintain many enset local varieties in their homegarden. The number of enset local varieties recorded per household was in the range of 5 to 56 . Most of the informants (52\%) cultivated 15 30 local varieties, $22 \%$ cultivated $10-15$ local varieties, and $16 \%$ of the informants cultivated 5-10 local varieties and only $10 \%$ of the informants cultivated more than 30 local varieties. The cultivation range of enset local varieties handled by informants in the study area were expressed in percentages in Figure 1.

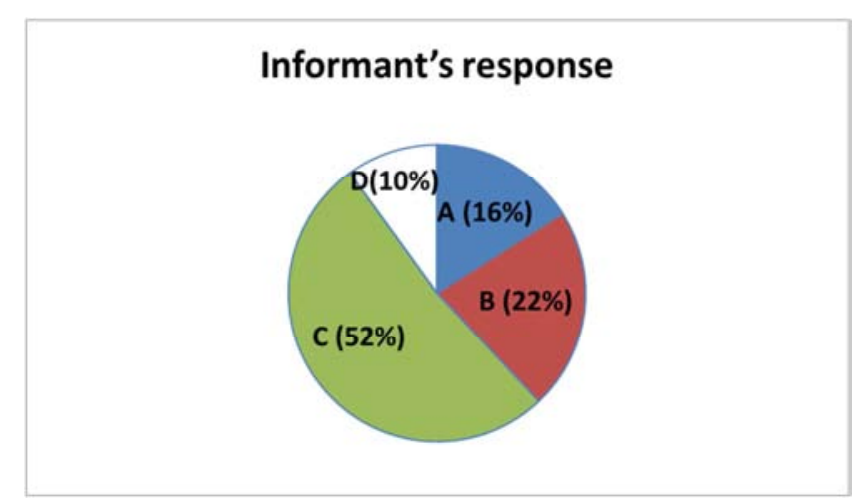

Figure 1. Cultivation range of enset local varieties handled by informants in the study area.

The least diversity was documented at Adancho and Hobech-Melisa study sites, which are found relatively at lower altitude. Relatively more diversity was documented at Gedelo-Geweda, Jeba-Dodoba and Qerekecho study sites.

All the informants in the study area reported that they can distinguish all of their enset local varieties growing in their farmland based on different morphological traits (leaf, midrib, petiole and pseudostem color, length and width). 
During discussion and semi-structured interview with informants, it was also found that the local people in the study area planted different enset local varieties based on several selection criteria such as nutritional quality, fiber quality, fermentation quality, high yield, early maturity, medicinal values, disease and drought resistance.

Ten most frequently mentioned enset local varieties were presented to key informants to be arranged based on high yield, fermentation quality and their early maturity. As a result of the preference ranking, 'Dirbo' became the first, 'Ongame' the second and 'Abatmerza' the third most preferred enset local variety for its high yield; 'Leqaqa', 'Gembewa' and 'Abatmerza' scored highest points (first to third, respectively) for their fermentation quality; and 'Sisqela', 'Gembewa' and 'Leqaqa' stood first to third, respectively for their early maturity (Table 1).

Table 1. Simple preference ranking of enset local varieties based on high yield, fermentation quality, early maturity and perceived importance / desirability.

\begin{tabular}{|c|c|c|c|c|c|c|c|c|c|c|c|c|c|}
\hline \multirow{2}{*}{ Selection criteria } & \multirow{2}{*}{$\begin{array}{l}\text { Enset local } \\
\text { variety }\end{array}$} & \multicolumn{12}{|c|}{ Key Informants (R) } \\
\hline & & R-1 & R-2 & $\mathbf{R}-3$ & R-4 & R-5 & R-6 & R-7 & $\mathbf{R}-8$ & R-9 & R-10 & Total & Rank \\
\hline \multirow[t]{10}{*}{ High yield } & Sisqela & 6 & 7 & 9 & 6 & 8 & 7 & 2 & 2 & 7 & 10 & 64 & 4 \\
\hline & Abatmerza & 8 & 9 & 4 & 5 & 7 & 9 & 8 & 7 & 9 & 5 & 71 & 3 \\
\hline & Ongame & 7 & 8 & 7 & 9 & 9 & 8 & 7 & 9 & 8 & 9 & 81 & 2 \\
\hline & Geshera & 2 & 6 & 5 & 8 & 6 & 4 & 5 & 5 & 5 & 7 & 53 & 6 \\
\hline & Dirbo & 10 & 10 & 10 & 10 & 10 & 10 & 10 & 10 & 10 & 6 & 96 & 1 \\
\hline & Gembewa & 9 & 5 & 2 & 7 & 3 & 5 & 6 & 4 & 6 & 8 & 55 & 5 \\
\hline & Sebera & 4 & 4 & 3 & 2 & 2 & 2 & 4 & 3 & 2 & 2 & 28 & 9 \\
\hline & Leqaqa & 3 & 2 & 1 & 1 & 1 & 1 & 1 & 1 & 1 & 1 & 13 & 10 \\
\hline & Dego & 5 & 3 & 6 & 4 & 4 & 3 & 3 & 6 & 3 & 3 & 40 & 8 \\
\hline & Sheleqe & - & - & 8 & 3 & 5 & 6 & 9 & 8 & 4 & 4 & 47 & 7 \\
\hline \multirow[t]{10}{*}{ Fermentation quality } & Sisqela & 2 & 3 & 4 & 3 & 3 & 2 & 1 & 6 & 10 & 3 & 37 & 7 \\
\hline & Abatmerza & 10 & 10 & 8 & 6 & 6 & 8 & 8 & 8 & 8 & 6 & 78 & 3 \\
\hline & Ongame & 9 & 9 & 6 & 5 & 4 & 5 & 6 & 4 & 5 & 8 & 61 & 5 \\
\hline & Geshera & 3 & 4 & 1 & 4 & 1 & 7 & 3 & 2 & 4 & 3 & 32 & 9 \\
\hline & Dirbo & 4 & 5 & 5 & 2 & 5 & 3 & 2 & 3 & 2 & 4 & 35 & 8 \\
\hline & Gembewa & 6 & 6 & 7 & 8 & 10 & 10 & 9 & 9 & 9 & 9 & 83 & 2 \\
\hline & Sebera & 7 & 8 & 9 & 9 & 7 & 6 & 7 & 10 & 6 & 7 & 76 & 4 \\
\hline & Leqaqa & 8 & 7 & 10 & 10 & 9 & 9 & 10 & 7 & 7 & 10 & 87 & 1 \\
\hline & Dego & 5 & - & 3 & 7 & 8 & 4 & 5 & 5 & 3 & 5 & 45 & 6 \\
\hline & Sheleqe & 1 & - & 2 & 1 & 2 & 1 & 4 & 1 & 1 & 1 & 14 & 10 \\
\hline \multirow[t]{10}{*}{ Early maturity } & Sisqela & 10 & 4 & 10 & 9 & 6 & 10 & 10 & 10 & 10 & 8 & 87 & 87 \\
\hline & Abatmerza & 2 & 10 & 7 & 5 & 1 & 6 & 6 & 6 & 7 & 6 & 56 & 56 \\
\hline & Ongame & 8 & 7 & 1 & 4 & 3 & 4 & 7 & 4 & 5 & 7 & 50 & 50 \\
\hline & Geshera & 9 & 3 & 2 & 3 & 4 & 9 & 2 & 2 & 9 & 3 & 46 & 46 \\
\hline & Dirbo & 7 & 5 & 3 & 2 & 2 & 2 & 5 & 3 & 3 & 2 & 34 & 34 \\
\hline & Gembewa & 6 & 9 & 6 & 7 & 10 & 7 & 9 & 9 & 6 & 9 & 78 & 78 \\
\hline & Sebera & 5 & 8 & 8 & 8 & 9 & 8 & 1 & 7 & 4 & 4 & 62 & 62 \\
\hline & Leqaqa & 5 & 6 & 9 & 10 & 8 & 5 & 8 & 8 & 8 & 10 & 77 & 77 \\
\hline & Dego & 3 & - & 5 & 6 & 7 & 3 & 4 & 5 & 2 & 6 & 41 & 41 \\
\hline & Sheleqe & - & - & 4 & 1 & 5 & 1 & 3 & 1 & 1 & 1 & 17 & 17 \\
\hline \multirow[t]{10}{*}{$\begin{array}{l}\text { Perceived importance / } \\
\text { desirability }\end{array}$} & Sisqela & 2 & 8 & 10 & 6 & 10 & 10 & 1 & 2 & 7 & 10 & 66 & 5 \\
\hline & Abatmerza & 10 & 7 & 6 & 7 & 9 & 8 & 6 & 8 & 9 & 6 & 76 & 2 \\
\hline & Ongame & 8 & 6 & 2 & 10 & 6 & 6 & 9 & 9 & 6 & 9 & 71 & 3 \\
\hline & Geshera & 3 & 9 & 1 & 9 & 8 & 4 & 5 & 3 & 5 & 4 & 51 & 6 \\
\hline & Dirbo & 5 & 10 & 9 & 2 & 7 & 9 & 10 & 10 & 10 & 7 & 79 & 1 \\
\hline & Gembewa & 9 & 4 & 5 & 8 & 4 & 7 & 7 & 7 & 8 & 8 & 67 & 4 \\
\hline & Sebera & 6 & 5 & 7 & 5 & 5 & 3 & 3 & 6 & 1 & 1 & 42 & 7 \\
\hline & Leqaqa & 7 & 3 & 8 & 4 & 1 & 5 & 2 & 5 & 4 & 3 & 42 & 7 \\
\hline & Dego & 4 & 2 & 3 & 3 & 3 & 2 & 4 & 4 & 3 & 2 & 30 & 9 \\
\hline & Sheleqe & 1 & 1 & 4 & 1 & 2 & 1 & 8 & 1 & 2 & 5 & 26 & 10 \\
\hline
\end{tabular}

\subsubsection{Enset Propagation and Cultivation System}

The key informants reported that enset is reproduced from suckers, which in turn are produced from the corm of an immature enset of 3-4 years old (locally called 'Era'). The mother corm pieces are obtained by removing the pseudostem leaving a small portion of the lower part attached with the corm, removing the roots, and cutting out the center or apical bud. The latter is done to stimulate more production of suckers by avoiding apical dominance. The corm is then buried and covered with manure and soil. After 3 to 4 months, suckers emerge and are left to grow for about a year. 
It was also reported that the corm would be dug out, and the one-year old suckers (called 'Dubo') would be separated and transplanted into a well-prepared land with added animal manure and allowed to grow for about a year. After the first transplantation, the growing stage of the enset plant and the plot would locally be called 'Sema'. After one year, 'Sema' (a 2-year old seedling) would be transplanted into another plot (i.e. second transplantation) and the growing stage of this enset plant and the plot would locally be named as 'Era'.

It was also found that after one year, 'Era' (a 3-year old seedling) would be transplanted into enset main field (i.e. the third and the last transplantation) and the growing stage of this enset plant would locally be called 'Wesho' (singular) or 'Wesse' (plural), which is the main enset plant. Informants reported 7 or 8 years as the average age of an enset plant.

\subsubsection{Enset Harvesting and Processing}

About 77\% (77) of the informants reported that enset is harvested just at flowering period, $12 \%$ (12) of them reported its harvest before flowering period and the remaining $11 \%$ (11) reported its harvest before and after flowering periods.

It was also reported that the enset plant would become fully matured on average at the age of 7-8 years. Enset can be harvested as food starting from the fifth year and as feed for livestock at the age of three years. The local people in the study area indicated that enset is commonly harvested at the age of 7-8 years, when it is fully matured.

Enset harvesting, when it is immature is not common in the study area. This is because the local people are aware of the fact that immature harvesting would give very less yield, poor quality of 'qocho' and fiber, less market value of 'bulla' (the most desirable enset food product). After all, it is a taboo to harvest immature enset plant as it is considered an indication of lower status in the society. It was also reported that immature harvesting occurs only during drought season (when there is no enough food and other alternative crops) and when enset plant is attacked by disease locally called 'Zera' and 'Beqoqo'.

Most of the informants, 53\% (53) were found to harvest on average about 50-100 enset plants per year. It was also found that the local people in the study area usually harvest three times within a year. Most commonly the greatest harvest takes place in December and January.

The study showed that, during harvesting, leaves and older leaf sheaths are removed from the plant and the pseudostem is stripped off until only the edible part remains. Then the pseudostem is usually cut into two equal parts (not less than one meter each). This is done for ease of processing and quality fiber production.

The upper half is locally called "Geneno" and the lower half is called "Beteo". The lower half of the pseudostem is either uprooted with the whole corm or cut and separated including the upper half of the corm, leaving the lower half of the corm in its place. This option depends upon individual's interest to process a fermenter (starter) from the lower half of the corm in different places or within its place.

Then, the two halves of the pseudostem and the upper half of the corm will be transported to the processing area, which is covered with enset leaves within the enset farm. Here, the leaf sheaths of both halves of the pseudostem are peeled off one by one and then decorticated (scraped) using a locallymade bamboo scraper (Sisa) to separate the pulp from the fiber. The corm is also grated separately with a locally made wooden tool with sharp serrated edge called "Qewo". Half of the grated corm serves as a fermenter (a starter) consisting fermented 'Kocho' to which various spices and herbs are added and the other half is processed with the pulp.

After the completion of decorticating and grating, the leaf sheath pulp is spread on fresh enset leaves covering the ground, after which the grated corm is spread on the processed pulp. The mixture of these contents are thoroughly mixed and placed into a pit lined with fresh enset leaves. After 7-15 days, the mixture is removed out of the pit and the pulp is squeezed and the liquid starch obtained is collected. Then the resultant starch is allowed to concentrate (precipitate) into a white powder. This results in one of the food products of enset known as 'Bulla'.

The remaining pulp is placed back into a pit and after 1520 days, it is taken out of the pit and mixed with a fermenting agent called "Gemama". The fermenter "Gemama" is prepared from the lower half of the corm by grating and adding various spices and herbs, and then placed in a pit for 15 days.

The thoroughly mixed contents of the pulp and the fermenting agent are put back into the pit and kept for 15-30 days. In every processing stage mentioned above, the contents of the pulp are turning, mixing and chopping both within the pit and out of the pit at intervals to ensure that the contents are well mixed and fermented. The fermented product of this process is called commonly 'Qocho' or 'Wasa' in the study area.

\subsection{Uses of Enset}

The local people in the study area reported that every part of the enset plant is used and nothing was found to be wasted. The pseudostem is used as food, medicine, and also used to produce a fibre. The dried leaf sheaths, locally called 'Hofecho' is used as wrappers for 'qocho', 'bulla', butter, and other items to transport to local markets. 'Hofecho' is also used as tying material for house and fence construction. The pulp from the dried leaf sheaths, locally called "Halamo" is used as cleaning rags and baby cushions.

The study showed that enset leaves are mainly used as animal forage. Fresh enset leaves are also used like mats, serving plates, as food wrappers and pit liners to process and store food products. The dried petioles and midribs, locally called 'Wedero' used to make mats locally called 'Endebero' or 'Jeba' and ropes. 'Wedero' is also used as tying material for house and fence construction and as fuel. The corm is also used as food and medicine.

Ten most frequently mentioned enset local varieties were presented to key informants to arrange them according to their perceived importance / desirability. The result showed that 'Dirbo', 'Abatmerza' and 'Ongame' scored highest 
points (first to third, respectively) (Table 1).

A direct matrix ranking of ten multi-purpose enset local varieties carried out on ten use criteria helped to order the local varieties according to their relative importance as

Table 2. Community ranking matrix of 10 multi-purpose enset local varieties by respondents on ten use criteria.

\begin{tabular}{|c|c|c|c|c|c|c|c|c|c|c|c|c|}
\hline \multirow{2}{*}{$\begin{array}{l}\text { Enset local } \\
\text { varieties }\end{array}$} & \multicolumn{12}{|c|}{ Key informants (R) } \\
\hline & Qocho & Amicho & Bulla & Fiber & Forage & Medicine & Wedero & Hofecho & Baking dough & Wrapping & Total & Rank \\
\hline Abatmerza & 78 & 60 & 77 & 59 & 61 & 51 & 52 & 57 & 61 & 63 & 619 & 4 \\
\hline Dego & 41 & 44 & 46 & 40 & 52 & 15 & 44 & 45 & 59 & 54 & 440 & 8 \\
\hline Dirbo & 41 & 26 & 38 & 71 & 87 & 28 & 72 & 89 & 93 & 92 & 637 & 2 \\
\hline Gembewa & 86 & 77 & 91 & 38 & 43 & 33 & 43 & 46 & 44 & 46 & 547 & 6 \\
\hline Geshera & 41 & 50 & 40 & 65 & 53 & 98 & 66 & 50 & 44 & 50 & 557 & 5 \\
\hline Leqaqa & 66 & 100 & 73 & 18 & 17 & 23 & 16 & 16 & 17 & 16 & 362 & 10 \\
\hline Ongame & 63 & 50 & 59 & 73 & 69 & 28 & 74 & 83 & 80 & 82 & 661 & 1 \\
\hline Sisqela & 52 & 30 & 34 & 94 & 68 & 27 & 94 & 80 & 77 & 77 & 633 & 3 \\
\hline Sheleqe & 18 & 13 & 19 & 57 & 72 & 37 & 59 & 51 & 44 & 37 & 407 & 9 \\
\hline Sebera & 63 & 88 & 73 & 33 & 27 & 65 & 29 & 32 & 31 & 32 & 473 & 7 \\
\hline
\end{tabular}

\subsection{Major Food Products of Enset}

Enset is primarily cultivated as a food crop and all the people in the study area consume enset products as staple food. Pseudostem and corm are the edible parts of enset in the study area. The major food products obtained from the enset plant are locally called 'Qocho' or 'Wasa', 'Bulla' and 'Amicho'.

\subsubsection{Qocho or Wasa}

'Qocho' is steam-baked flat-bread made from fermented perceived by the local community. From the community ranking matrix, it was found that 'Ongame', 'Dirbo' and 'Sisqela' are at the top of the list (Table 2).

Table 3. Simple preference ranking of enset local varieties based on their 'Kocho' quality, 'Bulla' quality and 'Amicho' quality.

\begin{tabular}{|c|c|c|c|c|c|c|c|c|c|c|c|c|c|}
\hline \multirow{2}{*}{ Selection criteria } & \multirow{2}{*}{$\begin{array}{l}\text { Enset local } \\
\text { variety }\end{array}$} & \multicolumn{12}{|c|}{ Key Informants (R) } \\
\hline & & R-1 & R-2 & R-3 & R-4 & $R-5$ & R-6 & R-7 & R-8 & R-9 & R-10 & Total & Rank \\
\hline \multirow[t]{10}{*}{ Kocho' quality } & Abatmerza & 10 & 10 & 9 & 9 & 10 & 7 & 7 & 9 & 9 & 4 & 84 & 1 \\
\hline & Sisqela & 2 & 1 & 10 & 3 & 6 & 3 & 1 & 8 & 8 & 10 & 52 & 6 \\
\hline & Gembewa & 9 & 9 & 4 & 10 & 5 & 9 & 8 & 10 & 10 & 9 & 83 & 2 \\
\hline & Ongame & 8 & 4 & 5 & 7 & 9 & 4 & 6 & 3 & 6 & 8 & 60 & 4 \\
\hline & Dirbo & 4 & 3 & 8 & 1 & 2 & 2 & 1 & 1 & 1 & 3 & 26 & 10 \\
\hline & Sebera & 6 & 8 & 6 & 8 & 8 & 10 & 9 & 7 & 2 & 1 & 65 & 3 \\
\hline & Geshera & 3 & 2 & 3 & 6 & 1 & 6 & 3 & 2 & 4 & 2 & 32 & 8 \\
\hline & Leqaqa & 7 & 7 & 1 & 5 & 7 & 8 & 5 & 5 & 5 & 6 & 56 & 5 \\
\hline & Etene & - & 6 & 7 & 4 & 4 & - & 10 & 6 & 7 & 5 & 49 & 7 \\
\hline & Dego & 5 & 5 & 2 & 2 & 3 & 1 & 4 & 4 & 1 & 1 & 28 & 9 \\
\hline \multirow[t]{7}{*}{ 'Bulla' quality } & Gembewa & 6 & 7 & 2 & 7 & 6 & 7 & 7 & 4 & 7 & 6 & 59 & 1 \\
\hline & Abatmerza & 7 & 5 & 5 & 3 & 5 & 6 & 5 & 3 & 5 & 7 & 51 & 2 \\
\hline & Sebera & 2 & 4 & 4 & 2 & 4 & 5 & 6 & 5 & 1 & 2 & 35 & 5 \\
\hline & Etene & - & 2 & 3 & 4 & 7 & - & 1 & 6 & 6 & 4 & 33 & 6 \\
\hline & Leqaqa & 4 & 6 & 7 & 5 & 2 & 4 & 3 & 7 & 2 & 5 & 45 & 3 \\
\hline & Torore & 3 & 3 & 6 & 6 & 3 & 3 & 4 & 2 & 4 & 3 & 37 & 4 \\
\hline & Ongame & 5 & 1 & 1 & 1 & 1 & 2 & 2 & 1 & 3 & 1 & 18 & 7 \\
\hline \multirow[t]{6}{*}{ 'Amicho' quality } & Leqaqa & 6 & 6 & 6 & 4 & 6 & 6 & 3 & 6 & 5 & 6 & 54 & 1 \\
\hline & Sebera & 5 & 4 & 2 & 1 & 4 & 2 & 2 & 1 & 1 & 2 & 24 & 5 \\
\hline & Torore & 4 & 3 & 3 & 5 & 2 & 3 & 4 & 3 & 3 & 3 & 33 & 4 \\
\hline & Tebere & 3 & 5 & 5 & 6 & 3 & 5 & 5 & 5 & 4 & 4 & 45 & 2 \\
\hline & Qouena & 2 & - & 4 & 3 & 5 & 4 & 6 & 4 & 6 & 5 & 39 & 3 \\
\hline & Astera & 1 & - & 1 & 2 & 1 & 1 & 1 & 2 & 2 & 1 & 12 & 6 \\
\hline
\end{tabular}




\subsubsection{Bulla}

'Bulla' is a water insoluble starchy food product obtained by squeezing the contents of the mixture of the decorticated leaf sheath and grated corm and then decanting the liquid part. 'Bulla' can be eaten as porridge or as flat bread. The local people in the study area reported 'bulla' as the best quality and the most preferred enset-derived food product.

Seven enset local varieties, most frequently mentioned by informants for 'bulla' production, were presented to key informants to arrange them according to 'bulla' quality. The result showed that 'Gembewa', 'Abatmerza' and 'Leqaqa' stood first to third, respectively (Table 3).

\subsubsection{Amicho}

This enset food product does not require any processing as to 'qocho' and 'bulla'. It is simply the inner part of the corm eaten boiled like potato. It is usually harvested for immediate consumption.
Preference ranking on six enset local varieties based on 'amicho' quality showed that 'Leqaqa', 'Tebere' and 'Qouena' scored highest points (first to third, respectively) (Table 3).

\subsection{Enset as a Source of Fiber}

The pseudostem part of an enset is an important source of fiber production. The fiber extracted by decorticating the leaf sheaths of the pseudostem is used locally for making ropes, mats, sacks, bags, and sieves and used as construction material (substituting nails). It is also sold in local markets for use by fiber factory called G-7.

Pairwise ranking of five enset local varieties was conducted based on their fiber quality. The result showed that 'Sisqela', 'Geshera' and 'Ongame' stood first to third, respectively (Table 4).

Table 4. Matrix of aggregate score of the pairwise ranking of five enset local varieties based on fiber quality.

\begin{tabular}{|c|c|c|c|c|c|c|c|c|c|c|c|c|}
\hline \multirow{2}{*}{$\begin{array}{l}\text { Enset local } \\
\text { variety }\end{array}$} & \multicolumn{12}{|c|}{ Key Informants (R) } \\
\hline & R-1 & R-2 & R-3 & R-4 & R-5 & R-6 & R-7 & R-8 & R-9 & R-10 & Total & Rank \\
\hline Sisqela & 4 & 4 & 4 & 4 & 4 & 4 & 4 & 4 & 4 & 4 & 40 & 1 \\
\hline Ongame & 1 & 1 & 2 & 2 & 2 & 2 & 0 & 2 & 1 & 2 & 15 & 3 \\
\hline Geshera & 2 & 3 & 0 & 3 & 3 & 1 & 3 & 3 & 3 & 3 & 24 & 2 \\
\hline Dirbo & 3 & 2 & 1 & 0 & 1 & 0 & 1 & 1 & 2 & 0 & 11 & 4 \\
\hline Sheleqe & 0 & 0 & 3 & 1 & 0 & 3 & 2 & 0 & 0 & 1 & 10 & 5 \\
\hline
\end{tabular}

\subsection{Medicinal Use of Enset}

In this study, 38 enset local varieties were documented as medicinal plants. All of these were used for treating both human and livestock ailments and the corm was found to be the most frequently utilized plant part. Among the 38 enset local varieties documented as medicinal plants, 17 were cited only by one of the hundred informants and the remaining 21 were cited by many of the informants. The most frequently cited enset local varieties for medicinal uses were 'Geshera' (28\%), followed by 'Tesa' (22\%), 'Qeqele' (21\%), 'Welagela' (16\%), and 'Cherqewa' (13\%) (Figure 2).

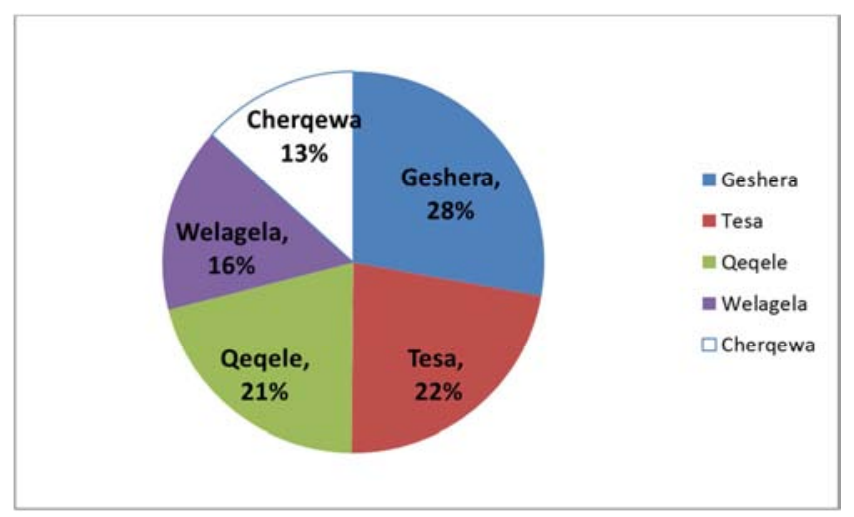

Figure 2. Medicinal use of enset local varieties as cited by informants in the study area.

During discussion and semi-structured interview with informants, it was found that the corm ('amicho') of 'Geshera' is used to cure broken bones and bone fractures; the corm of 'Tesa' is used to cure broken bones and to remove spines and similar objects from the body by bursting the swelling with pus; and the corm of 'Qeqele' (for humans) and all of its parts (for livestock) are used to discharge delayed placenta (afterbirth) and as an abortifacient. While the boiled corm of 'Welagela' is eaten, the liquid obtained from its pseudostem is used to wash the body and to cure skin problems such as scabies. The corm of 'Cherqewa' is used to cure broken bones, to remove spines from the body and used as an abortifacient.

\subsection{Socio-cultural Value of Enset}

The cultural significance of enset was reflected in the traditional songs and sayings of Kambaata language of the local people. One of the popular local songs says "Wesho ororo Wesho ororo, amicho-bisukuta, wedorochkomesmara, hoffechoko-mentafa, haberechko-mentafa, halanchoko-mehareba, Wesho ororo Wesho ororo." This song can be translated as "enset is great; its 'amicho' (food product) is like cake or bread, its 'wedro' (dried petioles and midribs) is like nail, its 'hofecho' (dried leaf sheaths) is like mat, its 'halancho' (the pulp from the dried leaf sheaths) is like cleaning rags; enset is great!". This local song describes enset as a multi-purpose crop and the uses of its different parts.

There are also other popular local songs and sayings that praise enset by describing it as all season food that can be 
harvested any time, as crop for food security and important for soil and water conservation.

It was observed that prestige and pride has been associated with maintaining many enset plants, diverse local varieties and rare local varieties in their homegardens. It was reported that people that do not cultivate and maintain enough enset plants in their gardens are considered as poor (food insecure) and lazy farmers and social outcasts.

\section{Discussion}

\subsection{Diversity of Enset Local Varieties}

A total of 154 enset local varieties were recorded from ten localities that were surveyed. As 65 of the 154 local varieties were cited by only 1 of the 100 informants, they might not be taken as a guarantee to sum the total number of local varieties to be 154 . But the remaining 89 local varieties, which were cited by many of the informants, are more than enough to show that the local people in the study area used and maintained very diverse enset local varieties, as compared to the 60 local varieties reported from Chenna and Decha districts of Kaffa Zone [12] and 86 local varieties reported from Sidama Zone [13].

\subsection{Emic Categories of Enset Local Varieties}

The two categories of enset local varieties, male and female categories were distinguished by a set of characteristics. The female category was characterized by its high quality of 'qocho', 'bulla', and 'amicho'. It is also characterized by high fermentation quality and early maturity, but low yielder and susceptible to disease and drought. The male category was characterized by its low quality of 'qocho', 'bulla', and 'amicho'. It is also characterized by low fermentation quality and late maturity, but provide high yield, strong fibers and tolerant to disease and drought. These results are in consistent with findings reported by Almaz Negash [14] and Yemane Tsehaye and Fassil Kebebew [12]. On the other hand, Zippel and Ludders [15] reported three categories of enset local varieties; male, female, and intermediate categories.

\subsection{Local Farming System}

Enset was found to be part of the major production and consumption system in the study area. The study showed that local people used and maintained several local varieties for their various qualities on their homestead, demonstrating the significance of in situ conservation in association with their use. Awegechew Teshome et al. [16] also indicated a similar relationship between farmers' selection criteria and crop diversity, that the more selection criteria employed, the more diverse varieties maintained. This fact is supported by Sato [17] which reported unique selection mode of human beings as an engine of diversification of local varieties.

The study revealed that the local people in the study area identified their enset local varieties based on different morphological traits such as leaf, midrib, petiole and pseudostem color, length and width. Zippel and Ludders [15] and Yemane Tsehaye and Fassil Kebebew [12] also reported similar variety identification criteria.

\subsection{Uses of Enset}

The study showed that enset is a multi-purpose crop that provides the local people with food, forage, fiber and construction material. It is also used as medicine, wrapping material, serving plates, cleaning rags and for making mats, sacks and ropes. It was also found that the local people utilized every part of the enset local varieties for various uses. This indicates the people's richer knowledge on enset local varieties, which enables them to utilize these genetic resources for diverse uses. This result agrees with that of previous study which states the wealth of knowledge and experience that indigenous people often acquire on local plant resources with the passage of time, through observation and trial and error on local plant resources [18].

\subsection{Major Food Products of Enset}

The present study revealed that the pseudostem and the corm parts of the enset plant are used as the main food sources in the study area, which is in agreement with Sato [17], Mohammed et al. [19] and Tefera Mekonen et al. [20]. Unlike the above observation, Yemane Tsehaye and Fassil Kebebew [12] recorded the use of leaf petioles as a source of food in Kaffa zone. The study also indicated that three major food products which are obtained from enset: 'qocho', 'bulla', and 'amicho'. 'Qocho' is produced in large quantities and consumed frequently, whereas 'bulla' is the best and most preferred enset food product. On the other hand, 'amicho' is harvested for its immediate use as food. A similar result was reported by Brandt et al. [21].

\subsection{Enset as Source of Fiber}

The study revealed that fiber is one of the most important products obtained from enset. Fiber was used in every household to make ropes, mats, sacks, bags, and other products for household use and marketed to supplement household income.

The study also indicated that certain enset local varieties such as 'Sisiqela', 'Geshera', 'Ongame', 'Dirbo', and 'Sheleqe' were preferred for strong fiber production. The fiber from enset was also sold in local markets for use by fiber factory.

Brandt et al. [21] reported that enset fiber has an excellent structure, and its strength is equivalent to the fiber of abaca, a world-class fiber crop and about 600 tons of enset fibers per year are sent to factories. It was also reported that the fiber from the leaf and pseudostem are comparable to that of Musa textilis [22]. This finding indicates the need to encourage the development of the fiber craft industry and promote fiber production in large scale for industrial use, so that the local people benefit from their genetic resources and associated traditional knowledge. 


\subsection{Medicinal Use of Enset}

The study showed that some enset varieties ('Geshera', 'Tesa', 'Qeqele', 'Welagela' and 'Cherqewa') are widely used as medicine to treat both human and livestock diseases. The corm and pseudostem of some enset varieties such as 'Wesse' were employed to cure broken bones of legs and arms, to facilitate a discharge of delayed placenta (afterbirth) and used as an abortifacieant [23]. These results are in consistent with findings reported by Brandt et al. [21] and Holscher and Schneider [24].

The study also revealed that an enset plant called 'Welagela' used to treat skin problems such as scabies. This result substantiates that some enset clones possess antimicrobial properties reported by Holscher and Schneider [24].

Some enset local varieties were found to cure more than one ailment, for example, 'Cherqewa' is used to cure broken bones, to remove spines from body and as an abortifacient. 'Tesa' is used to cure broken bones and to remove spines from body. The study indicated the need to screen these medicinal enset local varieties for their potential uses in pharmaceutical industry. Their promotion would enable the local people to benefit from the access of their genetic resources and associated traditional knowledge for bioprospecting.

\subsection{Socio-cultural Value of Enset}

The study indicated that enset has been involved in all cultural aspects of the local people in the study area, than any other plant species. The local people in the study area consider enset as their cultural heritage and a security against crop failure and food shortage. Similarly, Shank [25] describes the Wolayta area and the people as "the enset culture' or 'the enset people" being impressed with the importance apparently attached to this crop. The deep-rooted culture of using enset in daily lives from birth to death ceremonies is an important bio-cultural heritage of the Wolayta as well as Kembata Tembaro Communities [26].

The study also showed that prestige and pride to be associated with cultivation and maintenance of many enset plants in their homegarden. This indicates the socio-cultural value of enset that promote its conservation.

\section{Conclusion and Recommendation}

The local people in the study area have a rich knowledge on use, management and conservation of enset local varieties. This is reflected in their utilization of the diversified local varieties for various purposes and their maintenance of highly diverse enset local varieties in their homegardens. Most of the local people in the study area can identify, name, classify, relate, and tell the uses, merits and demerits of enset local varieties in their homegardens. The traditional management and conservation practices in the study area are generally found to be demand-driven. Recognizing the multiple uses of enset and its role in food security, the plant should be promoted as a future crop and a bioprospecting potential for industrial application. This, in turn, contributes to the conservation and sustainable utilization of enset genetic resource in the study area.

\section{References}

[1] Amanuel Assefa and Tesfahun Fenta (2006). Harnessing local and outsiders' knowledge: Experiences of multi-stakeholder partnership to promote farmer innovation in Ethiopia. Prolinnova Working Paper 12.

[2] Shewaye Deribe, Zemede Asfaw, Awegechew Teshome and Sebsebe Demissew (2002). Management of Agro-biodiversity in the Borkena watershed, South Wollo, Ethiopia: Farmers allocate crops /landraces to farm types. Ethiop. J. Biol. Sci. 1 (1): 13-36.

[3] Kiros Meles (2008). Temporal and spatial changes in land use patterns and biodiversity in relation to farm productivity at multiple scales in Tigray, Ethiopia. PhD Thesis. Wageniagen University, Wageningen, The Netherlands. pp. 170.

[4] Westphal, E. (1975). Agricultural Systems in Ethiopia. Wageningen: Centre for Agricultural Publishing and Documentation.

[5] Brandt, S. A. (1996). A model for the origins and evolution of enset food production. In: Proceedings from international workshop on enset. Enset-based Sustainable Agriculture in Ethiopia. pp. 172-187 (Tsedeke, A., Clifton, H., Steven, B. A. and Gebre-Mariam, S., eds.). Ethiopian Institute of Agricultural Research, Addis Ababa.

[6] Zippel, K. (2002). Enset (Enset ventricosum (Welw.) Cheesman) in subsistence farming systems in Ethiopia. Conference on international agricultural research for development, Witzenhou Sen, October, 9-11, 2002.

[7] Central Statistical Authority (CSA) (2007). Central Statistical Authority Statistical Abstract of Ethiopia, Addis Ababa.

[8] Central Statistical Authority (CSA) (2012). Report on area and production of major crops (Private Peasant holdings, Meher season (September - December 2011). Statistical bulletin, Vol. I. The Federal Democratic Republic of Ethiopia Central Statistical Agency, Addis Ababa, Ethiopia.

[9] Martin, G. J. (1995). Ethnobotany. A "people and plants" Conservation Manual. Worldwide Fund for Nature. Chapman and Hall, London.

[10] Alexiades, M. N. (1996). Selected Guidelines for Ethnobotanical Research. A field manual. The New York Botanical Garden, New York.

[11] Cotton, C. M. (1996). Ethnobotany: Principles and applications. Chichester, New York: John Wiley and Sons Ltd.

[12] Yemane Tsehaye and Fassil Kebebew (2006). Diversity and cultural use of enset (Enset ventricosum (Welw.) Cheesman) in Bonga in situ conservation site, Ethiopia. Ethnobotany Research and Applications 4: 147-157.

[13] Bizuayehu Tesfaye and Ludders, P. (2003). Diversity and distribution patterns of enset landraces in Sidama, Southern Ethiopia. Kluwer Academic, Netherlands. Genetic Resources and Crop Evaluation 50: 359-371. 
[14] Almaz Negash (2001). Diversity and conservation of enset (Ensete ventricosum (Welw.) Cheesman) and its relation to household food and livelihood security in south western Ethiopia. PhD Thesis. Wageningen Universiteit.

[15] Zippel, K. and Ludders, P. (2005). The Global food and product chain dynamics, innovations, conflicts, strategies: Ensete ventricosum in Ethiopia: The need to grow more than one landraces. Deutscher Tropentag, October 11-13, 2005, Hohenheim.

[16] Awegechew Teshome, Fahring, L., Torrance, J. K., Lambert, J. D., Arnason. T. J. and Baum, B. R. (1999). Maintenance of sorghum (Sorghum bicolor, Poaceae) landrace diversity by farmers' selection in Ethiopia. Econ. Bot. 53 (1): 79-88.

[17] Sato, Y. (2009). Ethnobotanical study of local practices maintaining diversity of banana (Musa spp.) and enset (Enset ventricosum in East African Highland). Kyoto Working Papers on Area Studies NO. 61 (G-COE series 59).

[18] Hoft, M., Barik, S. K. and Lykke, A. M (1999). Quantitiative ethnobotany. Application of multivariate and statistical analysis in ethnobotany. People and Plants Working Paper 6. UNESCO, Paris.

[19] Mohammed, B., Martin Gabel, and Karlsson, L. M. (2013). Nutritive values of the drought tolerant food and fodder crop enset. African Journal of Agricultural Research 8 (20): 23262333.

[20] Tefera Mekonen, Mirutse Giday and Ensermu Kelbessa (2015). Ethnobotanical study of homegarden plants in Sebeta-
Awas District of the Oromia Region of Ethiopia to assess use, species diversity and management practices. Journal of Ethnobiology and Ethnomedicine 11: 64.

[21] Brandt, S. A., Spring, A., Hiebsch, C., McCabe, J. T., Endale Tabogie, Mulugeta Diro, Gizachew, W-Michael, Gebre Yntiso, Shigeta, M. and Shiferaw Tesfaye (1997). The Tree against Hunger. Enset-based Agricultural Systems in Ethiopia. American Association for the Advancement of Science.

[22] Afza, R., Van Dure, M. and Morpurgo, R. (1996). Regeneration of Ensete ventricosum through somatic embryogenesis and adventitious buds. Plant Cell Reports 15: 445-448.

[23] Melesse Maryo and Sileshi Nemomissa and Tamirat Bekele (2015). An ethnobotanical study of medicinal plants of the Kembatta ethnic group in Enset-based agricultural landscape of Kembatta Tembaro (KT) Zone, Southern Ethiopia. Asian Journal of Plant Science and Research 5 (7): 42-61.

[24] Holscher, D. and Schneider, B. (1998). Phenylophenalenones from Ensete ventricosum. Phyotochemistry 49: 2155-2177.

[25] Shank, R. (1994). The Enset Culture. A Technical Report on Ensete ventricosum or 'False Banana'. UNDP, Emergencies Unit for Ethiopia.

[26] Temesgen Magule Olango, Bizuayehu Tesfaye, Catellani, M. and Mario Enrico Pè (2014). Indigenous knowledge, use and on-farm management of enset (Ensete ventricosum (Welw.) Cheesman) diversity in Wolaita, Southern Ethiopia. Journal of Ethnobiology and Ethnomedicine 10: 41. 